\title{
In vitro effects of 2-methoxyestradiol on cell morphology and Cdc2 Kinase activity in SNO oesophageal carcinoma cells
}

\author{
Annie Joubert* and Sumari Marais \\ Department of Physiology, University of Pretoria, Pretoria, South Africa
}

The effects of $1 \times 10^{-6} \mathrm{M}$ exogenous 2-methoxyestradiol (2 ME) were determined on cell morphology and cell division cycle (Cdc) 2 kinase activity in SNO oesophageal carcinoma cells. Mitotic indices revealed an increase in metaphase cells $(11.2 \%)$ when compared to the $0.5 \%$ vehicle-treated cells after $18 \mathrm{~h}$ of exposure to $2 \mathrm{ME}$. Vehicletreated control cells did not show any hallmarks of apoptosis after $18 \mathrm{~h}$ of exposure to dimethyl sulphoxide. Only $0.5 \%$ of $2 \mathrm{ME}$-treated cells showed characteristics of apoptosis. Conversely, increased morphological hallmarks of apoptosis were observed in SNO-treated cells after $21.5 \mathrm{~h}$ of $2 \mathrm{ME}$ exposure. When compared to the $0.5 \%$ in vehicle-treated cells, $4.7 \%$ of cells were in apoptosis. Furthermore, $34.1 \%$ of cells were blocked in metaphase after $21.5 \mathrm{~h}$ of $2 \mathrm{ME}$ exposure compared to $0.6 \%$ of vehicle-control cells. In addition, Cdc2 kinase activity was statistically significantly increased $(1.3$-fold) $(p<0.005)$ in $2 \mathrm{ME}$-treated cells when compared to vehicle-treated controls. The present preliminary study suggests that the accumulation observed in metaphase cells and the increase in Cdc2 kinase activity caused by $2 \mathrm{ME}$ are consistent with morphological hallmarks of mitotic arrest and disrupted mitotic spindle formation, thus leading to induction of apoptosis in SNO cells.

\section{INTRODUCTION}

2-Methoxyestradiol (2 ME) is a 17-beta estradiol metabolite regarded as an anti-mitotic drug and tubulin poison that inhibits growth and induces apoptosis in a large variety of tumour and non-tumour cell lines. ${ }^{1-}$ ${ }^{3} 2 \mathrm{ME}$ exerts both anti-angiogenic and anti-tumour effects regardless of the cell's hormone receptor status and is responsible for mitotic accumulation and abnormal mitotic spindle formation in both estrogen receptor (ER) positive and ER negative cells. ${ }^{4-6}$ As a consequence, this endogenous estradiol metabolite has emerged as a promising anti-cancer agent. ${ }^{5}$

Recent evidence has implicated $2 \mathrm{ME}$ in the activation of c-Jun NH2-terminal kinase signalling, generation of reactive oxygen species and induction of apoptosis via both the extrinsic and intrinsic pathways. JNK is involved in the phosphorylation and inactivation of the pro-apoptotic protein $\mathrm{Bcl}-2$, thus contributing to the induction of apoptosis. ${ }^{7},{ }^{8}$ It has been demonstrated that $2 \mathrm{ME}$ is responsible for the upregulation of death receptor 5 expression in vitro and in vivo, thereby activating the extrinsic pathway of apoptosis. However, the contribution of the extrinsic and intrinsic pathways of apoptosis induction appears to vary depending on the cell type. ${ }^{4}$

Research has shown that $2 \mathrm{ME}$ exhibits a biphasic pattern on cell proliferation at concentrations ranging from $10^{-8}$ to $10^{-5} \mathrm{M}$, namely a stimulatory effect at low concentrations and an inhibitory effect at the highest concentration. ${ }^{2}$ Dose-dependent studies conducted in our laboratory have demonstrated that a concentration of $10^{-6} \mathrm{M} 2 \mathrm{ME}$ reduced cell numbers by $40 \%$ and $60 \%$ in SNO and WHCO3 oesophageal carcinoma cells, respectively. ${ }^{9}$ Light and electron microscopy demonstrated cell shrinkage, membrane blebbing, condensed chromatin, nuclear fragmentation and micro-nuclei formation after $24 \mathrm{~h}$ of WHCO3 and SNO cells exposure to $10^{-6} \mathrm{M} 2 \mathrm{ME}$. Flow cytometric analysis revealed that $10^{-6} \mathrm{M} 2 \mathrm{ME}$ was also responsible for spindle disruption and $a G_{2} / M$ arrest of these cells thereby preventing them from proceeding through the cell cycle. ${ }^{9}$

Initial preclinical data demonstrated that $2 \mathrm{ME}$ might be used to treat multiple myeloma, sarcoma and other solid tumours thus rendering it as a potential anti-cancer agent when compared to conventional 
chemotherapeutic treatments. ${ }^{4,10,11}$ However, the exact action mechanism of 2 ME is complex, still not clearly defined and appears to vary according to cell type.,12 The aim of this preliminary study was to investigate the mechanism of action of $2 \mathrm{ME}$ in an oesophageal carcinoma cell line, by determining the influence of $2 \mathrm{ME}$ on cytoplasmic and nuclear morphology, as well as on cell division cycle (Cdc) 2 kinase activity as a cell cycle regulatory component.

\section{MATERIALS AND METHODS}

\section{Materials}

$2 \mathrm{ME}$, minimum essential medium eagle with Earle's salts, L-glutamine and $\mathrm{NaHCO}_{3}(\mathrm{MEM})$, Trypsi-nEDTA and Trypan blue were supplied by Sigma Chemical Co. (St. Louis, MO, USA). Heat-inactivated foetal calf serum (FCS), sterile cell culture flasks and plates were obtained through Sterilab Services (Kempton Park, Johannesburg, South Africa). Phosphate buffered saline (PBS) was purchased from GIBCO BRL (USA). Penicillin, streptomycin and fungizone were obtained from Highveld Biological (Sandringham, SA). Haematoxylin, eosin, ethanol, xylol and Entellan® fixative were purchased from Merck (Darmstadt, Germany). The MESACUP Cdc2 Kinase Assay Kit and HCK-gel suspension were purchased from MBL Medical \& Biological Laboratories (Nagoya, Japan). Cdc2 reaction buffer, biotinylated MV peptide, peroxidase (POD) conjugated streptavidin, wash concentrate (10x PBS), substrate $A$ (o-phenylenediamine), substrate $B\left(\mathrm{H}_{2} \mathrm{O}_{2}\right)$, stop solution $\left(20 \% \mathrm{H}_{3} \mathrm{PO}_{4}\right)$ and phosphorylation stop reagent (PBS containing $50 \mathrm{mM}$ EDTA) were supplied with the kit. ATP, Tris-HCl, EDTA, EGTA, Brij35, PMSF, beta-glycerophosphate, $\mathrm{Na}_{3} \mathrm{VO}_{4}, 2$-mercaptoethanol and the protease inhibitor cocktail were supplied by Sigma-Aldrich (St. Louis, USA). NaCl was purchased from Associated Chemical Enterprises (Southdale, South Africa), $\mathrm{MgCl}_{2}$ from Merck (Darmstadt, Germany) and HEPES from BDH Laboratory Supplies (Poole, England). All other chemicals were of analytical grade and supplied by Sigma Chemical Co. (St. Louis, MO, USA). The SNO oesophageal carcinoma cell line was purchased from Highveld Biological (Sandringham, SA). SNO cells are described as a non-keratinizing squamous epithelium cell line.

\section{Cell culture}

Cells were grown as monolayers in MEM at $37^{\circ} \mathrm{C}$ in a humidified atmosphere containing $5 \% \mathrm{CO}$. Media were supplemented with $10 \%$ heat-inactivated FCS, penicillin $(100 \mu \mathrm{g} / \mathrm{L})$, streptomycin $(100 \mu \mathrm{g} / \mathrm{L})$ and fungizone $(250 \mu \mathrm{g} / \mathrm{L})$. Non-viable cells were excluded with the Trypan blue staining procedure. Stock solutions of $2 \mathrm{ME}$ were prepared in DMSO at concentrations of $2 \times 10^{-3} \mathrm{M}$ and stored at room temperature. The DMSO content of the final dilutions never exceeded $0.1 \%(\mathrm{v} / \mathrm{v})$. Control experiments showed that $0.1 \%$ DMSO had no toxic effects on the SNO cells.

\section{Light microscopy}

In an attempt to obtain more insight into the anti-proliferative effect of $2 \mathrm{ME}$ observed in cell growth studies previously conducted in our laboratory, ${ }^{9}$ haematoxylin and eosin cell staining was used to determine the morphological characteristics of cytoplasm and nuclear components of SNO cells after exposure to $10^{-6} \mathrm{M} 2 \mathrm{ME}$. The latter concentration was chosen, since it has been revealed that $2 \mathrm{ME}$ displays a biphasic pattern on cell proliferation at concentrations ranging from $10^{-8}$ to $10^{-5} \mathrm{M}$, namely a stimulatory effect at low concentrations and an inhibitory effect at the highest concentration. 2 ME caused the strongest inhibitory effect at a concentration of $10^{-6} \mathrm{M}^{2}$ Exponentially growing SNO cells were seeded at $3 \times 10^{5}$ cells per well in 6 -well plates on heat-sterilized coverslips. After a $24 \mathrm{~h}$ incubation period at $37^{\circ} \mathrm{C}$ to allow for cell adherence, cells were exposed to $1 \times 10^{-6} \mathrm{M} 2 \mathrm{ME}$ and incubated for 18 and $21.5 \mathrm{~h}$, respectively at $37^{\circ} \mathrm{C}$. Exposure times of 18 and $21.5 \mathrm{~h}$ were chosen to monitor the increase in metaphase cells, since previous results in our laboratory had revealed that peak occurrence of apoptosis occurs after $24 \mathrm{~h}$ of exposure to $2 \mathrm{ME}$ in SNO cells. ${ }^{9}$ Cells were fixed in Bouin's fixative for 60 min after exposure to $2 \mathrm{ME}$ and stained by standard haematoxylin and eosin staining procedures. To investigate $2 \mathrm{ME}$ 's influence on cell proliferation, mitotic indices of vehicle-treated cells, as well as $2 \mathrm{ME}-$ exposed cells were also determined on the stained slides by counting 1000 cells on every coverslip. 


\section{Cell cycle checkpoint regulatory molecule-Cdc2 kinase assay}

SNO cells were grown in $75 \mathrm{~cm}^{2}$ flasks until $80 \%$ confluency and exposed to $1 \times 10^{-6} \mathrm{M} 2 \mathrm{ME}$ for $21.5 \mathrm{~h}$. Since the activation of Cdc2 kinase is vital for the initiation of mitosis and since $2 \mathrm{ME}$ caused a prominent block in metaphase after $21.5 \mathrm{~h}$ of exposure, the influence of $2 \mathrm{ME}$ was determined on SNO Cdc2 kinase activity after $21.5 \mathrm{~h}$ of exposure. Subsequently, cells were harvested and washed (three times) with PBS. Cells $\left(2 \times 10^{7}\right)$ were suspended in $1000 \mu$ sample buffer $(50 \mathrm{mM}$ Tris- $\mathrm{HCl}, \mathrm{pH} 7.5,0.5$ $\mathrm{mM} \mathrm{NaCl}, 5 \mathrm{mM}$ EDTA, 2mM EGTA, 0.01\% Brij35, $1 \mathrm{mM}$ phenyl methyl sulfonyl fluoride, $25 \mathrm{mM}$ betaglycerophosphate, $1 \mathrm{mM} \mathrm{Na}_{3} \mathrm{VO}_{4}, 50 \mathrm{mM}$ mer-captoethanol, $0.08 \%$ protease inhibitor cocktail) and lysed by sonication on ice. Cell extracts were centrifuged for $1 \mathrm{~h}$ at $100 \mathrm{000g}$. The protein content was determined by the Bradford method. ${ }^{14}$ Twenty microlitres of the HCK-gel was prepared by washing twice with sample buffer before it was incubated with $300 \mu$ of cell extract for $1 \mathrm{~h}$ on ice. After incubation, the HCK-gel was washed three times in sample buffer and twice with 2nd washing buffer (25 mM HEPES buffer, $\mathrm{pH} 7.5$ and $10 \mathrm{mM} \mathrm{MgCl}$ ), followed by centrifugation for $5 \mathrm{~min}$ at $1500 \mathrm{~g}$. The phosphorylation reaction was assembled on ice, by adding $5 \mu$ of the gel sediment, $5 \mu \mathrm{l} 10 \times \mathrm{Cdc} 2$ reaction buffer, $5 \mu \mathrm{l}$ biotinylated MV peptide and $30 \mu$ distilled water. The reaction was initiated by adding $5 \mu l, 1 \mu M$ ATP and incubated for $30 \mathrm{~min}$ at $30^{\circ} \mathrm{C}$. Subsequently the reaction was terminated by the addition of $200 \mu \mathrm{l}$ phosphorylation stop solution and the reaction mixture was centrifuged for $20 \mathrm{~s}$ at $11 \mathrm{000 \textrm {g }}$. A $100 \mu \mathrm{l}$ sample of reaction mixture was transferred to the microwell strips coated with monoclonal antibody $4 \mathrm{~A} 4$, provided with the kit. After $1 \mathrm{~h}$ incubation at $25^{\circ} \mathrm{C}$, the wells were washed five times with wash solution and $100 \mu \mathrm{POD}$ conjugated streptavidin was added to each well. After $30 \mathrm{~min}$ incubation at $25^{\circ} \mathrm{C}$, the wells were washed five times with wash solution and $100 \mu \mathrm{l} \mathrm{POD} \mathrm{substrate} \mathrm{solution} \mathrm{was} \mathrm{added} \mathrm{to} \mathrm{each}$ well. The microwell strips were incubated for $5 \mathrm{~min}$ at $25^{\circ} \mathrm{C}$ before $100 \mu \mathrm{l}$ stop solution was added to each well and the absorbance read at $450 \mathrm{~nm}$ in an ELx800 Universal Microplate Reader (Bio-Tek Instruments Inc., Analytical Diagnostic Products, Weltevreden, South Africa).

\section{Statistics}

Data were obtained from independent experiments. Results obtained are shown as the mean \pm SD and were statistically analyzed for significance using the analysis of variance (ANOVA)-single factor model followed by a two-tailed Student's t-test. Means are presented in bar charts, with T-bars referring to standard deviations. $p$-Values $<0.05$ were regarded as statistically significant and indicated by an * or number as indicated in the legends.

\section{RESULTS}

\section{Light microscopy}

The effects of $1 \times 10^{-6} \mathrm{M} 2 \mathrm{ME}$ were determined on cell morphology in SNO oesophageal carcinoma cells and compared to vehicle-treated controls after $18 \mathrm{~h}$ (Figure 1A,B) and $21.5 \mathrm{~h}$ (Figure 2A,B) of exposure, respectively. As already mentioned, exposure times of 18 and $21.5 \mathrm{~h}$ were chosen to monitor the increase in metaphase cells, since previous results in our laboratory had revealed that peak occurrence of apoptosis occurs after $24 \mathrm{~h}$ of exposure to $2 \mathrm{ME}$ in SNO cells. ${ }^{9}$ 
A

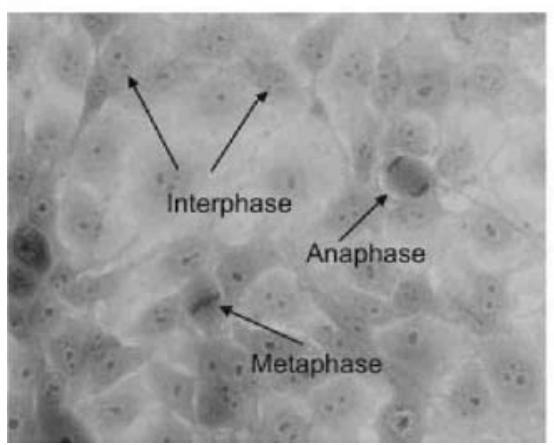

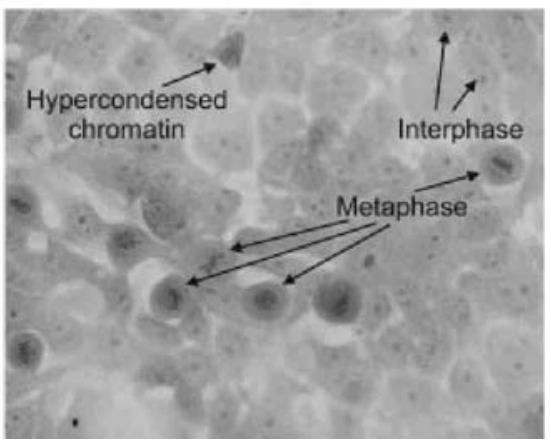

Figure 1. Haematoxylin and Eosin staining of SNO cells after $18 \mathrm{~h}$ of exposure to vehicle (A) and $1 \times 10^{-6} \mathrm{M} 2 \mathrm{ME}(\mathrm{B})$, respectively (400x magnification). Control SNO cells showed normal cell division including a cell in metaphase and anaphase. Interphase cells were also observed (A). Treated cells showed an increase in metaphase cells and cells with hypercondensed chromatin (B). Interphase cells were also observed (B)

A

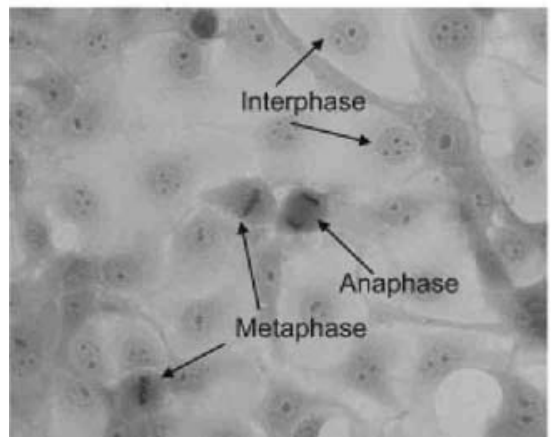

B

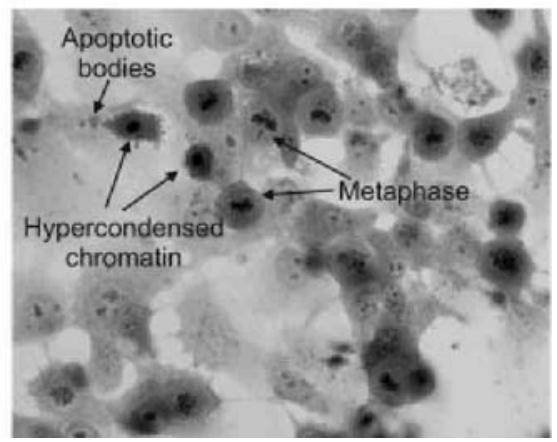

Figure 2. Haematoxylin and Eosin staining of SNO cells after $21.5 \mathrm{~h}$ of exposure to vehicle (A) and $1 \times 10^{-} \mathrm{M} 2 \mathrm{ME}(\mathrm{B})$, respectively (400x magnification). Control SNO cells showed interphase cells and normal cell division including a cell in metaphase and anaphase (A). Treated cells showed an increase in metaphase cells, cells with hypercondensed chromatin and apoptotic bodies (B)

The SNO control showed normal cell division including a cell in metaphase and anaphase after $18 \mathrm{~h}$ of exposure to DMSO. Interphase cells were also observed (Figure 1A). Treated cells showed an increase in metaphase cells and revealed hypercondensed chromatin after $18 \mathrm{~h}$ of exposure (Figure 1B). Interphase cells were also observed (Figure 1B). The SNO control revealed interphase cells and normal cell division including a cell in metaphase and anaphase after $21.5 \mathrm{~h}$ of exposure to DMSO (Figure 2A). Treated cells showed an increase in metaphase cells, cells with hypercondensed chromatin and apoptotic bodies after $21.5 \mathrm{~h}$ of exposure (Figure 2B). Mitotic indices demonstrated an increase in metaphase cells $(11.2 \%)$ when compared to the $0.5 \%$ vehicle-treated cells after $18 \mathrm{~h}$ of exposure to 2 ME (Figure 3). Vehicle-treated control cells did not show any hallmarks of apoptosis after $18 \mathrm{~h}$ of exposure to dimethyl sulphoxide. Only $0.5 \%$ of 2 ME-treated cells showed characteristics of apoptosis (Figure 3). Conversely, increased morphological hallmarks of apoptosis were observed in SNO-treated cells after $21.5 \mathrm{~h}$ of $2 \mathrm{ME}$ exposure. Mitotic indices demonstrated an increase in apoptotic cells (4.7\%) when compared to the $0.5 \%$ vehicle-treated cells after $21.5 \mathrm{~h}$ of exposure to $2 \mathrm{ME}$ (Figure 4). Furthermore, $34.1 \%$ of cells were blocked in metaphase after $21.5 \mathrm{~h}$ of $2 \mathrm{ME}$ exposure compared to $0.6 \%$ of vehicle-control cells (Figure 4). 


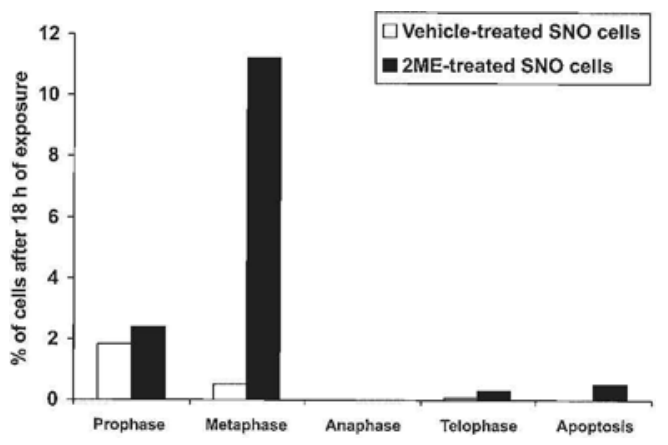

Figure 3. Mitotic indices of SNO cells after $18 \mathrm{~h}$ of exposure to vehicle and $2 \mathrm{ME}$, respectively, expressed as a percentage of a thousand cells counted. An increase in metaphase cells (11.2\%) was observed when compared to the $0.5 \%$ vehicle-treated cells. SNO control cells did not show any hallmarks of apoptosis. Only $0.5 \%$ of 2 ME-treated cells showed characteristics of apoptosis

\section{Cell cycle checkpoint regulatory molecule-Cdc2 kinase assay}

Since activation of Cdc2 kinase is fundamental for the initiation of mitosis and since 2 ME caused a prominent block in metaphase after $21.5 \mathrm{~h}$ of exposure, the influence of $1 \times 10^{-6} \mathrm{M} 2 \mathrm{ME}$ was determined on SNO Cdc2 kinase activity after $21.5 \mathrm{~h}$ of exposure and compared to vehicle-treated controls. Cdc2 kinase activity was statistically significantly increased $(1.3$-fold $)(p<0.005)$ in 2 ME-treated cells when compared to vehicle-treated controls (Figure 5).

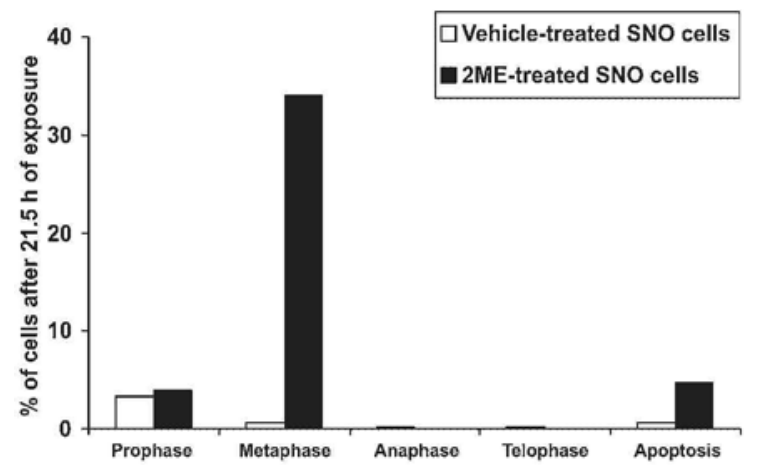

Figure 4. Mitotic indices of SNO cells after 21.5h of exposure to vehicle and $2 \mathrm{ME}$, respectively, expressed as a percentage of a thousand cells counted. SNO-treated cells showed an increase in apoptotic cells $(4.7 \%)$ when compared to the $0.5 \%$ vehicletreated cells. In metaphase, $34.1 \%$ of $2 \mathrm{ME}$-exposed cells were blocked compared to $0.6 \%$ of vehicle-control cells

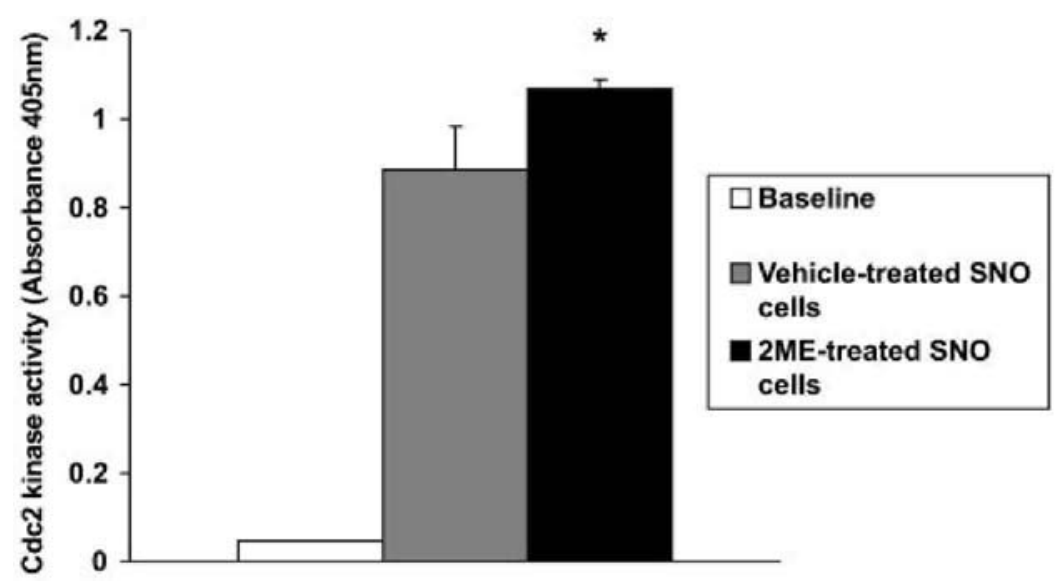

Figure 5. Cdc2 kinase activity of vehicle- and 2 ME-treated SNO cells, respectively, after $21.5 \mathrm{~h}$ of exposure. 2 ME caused a statistically significant increase (1.3-fold) when compared to vehicle-treated controls. The baseline represents a background reading of the Cdc2 kinase assay performed as described without cells in growth medium. $p$-Values $<0.05$ were regarded as statistically significant and indicated by an on the graph 


\section{DISCUSSION}

Several researchers have demonstrated 2 ME's biological activities in endothelial cells and in a diverse variety of tumour and non-tumour cell types. ${ }^{1,5,6,9,15,16}$ We have previously confirmed antiproliferative effects and morphological hallmarks of apoptosis in 2 ME-exposed HeLa, as well as WHCO3 squamous oesophageal carcinoma cells and revealed that $2 \mathrm{ME}$ was responsible for an altered ratio of Bax/ Bcl-2 in favour of Bax suggesting that this could lead to the induction of apoptosis in both these cells. ${ }^{17,18}$ However, the exact action mechanism of $2 \mathrm{ME}$ is complicated, still not clearly defined and appears to vary according to cell type.

In this pilot study, we investigated the influence of $2 \mathrm{ME}$ on cytoplasmic and nuclear morphology, as well as on Cdc 2 kinase activity as a cell cycle regulatory component in the SNO oesophageal carcinoma cell line. $2 \mathrm{ME}$ was responsible for an accumulation in metaphase cells and an increase in Cdc2 kinase activity, consistent with morphological hallmarks of mitotic arrest and disrupted mitotic spindle formation. Wang et al. stated that an accumulation of cells with condensed chromatin is characteristic of a mitotic block. ${ }^{9}$ Hypercondensed chromatin was also observed in the 2 ME-treated SNO cells. Similarly Attalla et al. revealed that $2 \mathrm{ME}$ was responsible for a metaphase block in Jurkat cells.

2 ME-treated SNO cells showed a high percentage of dividing cells, but most of these cells were abnormal and blocked in metaphase. Several studies have demonstrated that mitotic arrest precedes the induction of apoptosis, thus explaining the increase in apoptotic cells concomittent with the increase in the amount of cells blocked in metaphase. ${ }^{21}{ }^{22}$ However, Golebiewska et al. revealed that osteosarcoma cells exposed to $1 \times 10^{-6} \mathrm{M} 2 \mathrm{ME}$ were arrested in $\mathrm{G} 1$ thereby supporting the hypothesis that the action mechanisms of $2 \mathrm{ME}$ are dependent on cell type. ${ }^{21}$

Activation of $\mathrm{Cdc} 2$ is vital for the initiation of mitosis, while inactivation of Cdc2 is required for mitotic exit. Prolonged Cdc2 activity can maintain the cell in the mitotic state for an extended period until specified conditions are met for mitotic exit. ${ }^{23}$ Consequently, the increased Cdc2 activity observed in 2 ME-treated SNO cells is consistent with the observed morphological hallmarks of mitotic arrest. Prolonged mitotic arrest may result in apoptosis. Previous research has reported an increase in Cdc2 kinase activity during apoptosis. ${ }^{24-26}$ Van Zijl reported an increase in Cdc2 kinase activity, as well as an increase in the amount of apoptotic cells in the tumourigenic MCF-7 cell line after exposure to $2 \mathrm{ME}$. However, in contrast to the latter finding, only a slight elevation of Cdc2 kinase activity, as well as a less pronounced increase in the amount of apoptotic cells were observed in the $2 \mathrm{ME}$-exposed non-tumourigenic MCF-12A cell line. ${ }^{16}$

Although the exact mechanism of 2 ME's action and the role of key molecules influenced in oesophageal carcinoma cells require further investigation, the present study suggests that the accumulation observed in metaphase cells and the increase in Cdc2 kinase activity caused by $2 \mathrm{ME}$ are consistent with morphological hallmarks of mitotic arrest and disrupted mitotic spindle formation, thus leading to induction of apoptosis in SNO cells.

\section{REFERENCES}

1. Ghosh R, Ott AM, Seetharam D, Slaga TJ, Kumar AP. Cell cycle block and apoptosis induction in a human melanoma cell line following treatment with 2-methoxyoestradiol: therapeutic implications? Melanoma Res 2003; 13: 119-127.

2. Lippert $\mathrm{C}$, Seeger $\mathrm{H}$, Mueck AO. The effect of endogenous estradiol metabolites on the proliferation of human breast cancer cells. Life Sci 2003; 72: 877-883.

3. Tinley TL, Leal RM, Randall-Hlubek DA, et al. Novel 2-methoxyestradiol analogues with antitumor activity. Cancer Res 2003; 63: 1538-1549.

4. Mooberry SL. Mechanism of action of 2-methoxyestradiol: new developments. Drug Resist Updat 2003; 6: 355361.

5. Mueck AO, Seeger H, Huober J. Chemotherapy of breast cancer-additive anticancerogenic effects by 2methoxyestradiol? Life Sci 2004; 75: 1205-1210.

6. Seegers JC, Aveling ML, Van Aswegen CH, Cross M, Koch F, Joubert WS. The cytotoxic effects of estradiol-17 beta, cate-cholestradiols and methoxyestradiols on dividing MCF-7 and HeLa cells. J Steroid Biochem 1989; 32 : 
797-809.

7. Basu A, Castle VP, Boziane M, Bhalla K, Haldar S. Crosstalk between extrinsic and intrinsic cell death pathways in pancreatic cancer: synergistic action of estrogen metabolite and ligands of death receptor family. Cancer Res 2006; 66: 4309-4318.

8. Bu S, Bluakat A, Fu X, Heldin NE, Landstrom M. Mechanisms for 2-methoxyestradiol-induced apoptosis of prostate cancer cells. FEBS Lett 2002; 531: 141-151.

9. Thaver V. Mechanism(s)of apoptosis induction by 2-methoxyes-tradiol, an estrogen metabolite, in SNO and WHCO3 oesopha-geal carcinoma cell lines. M.Sc. Dissertation, 2003; Department of Physiology, University of Pretoria, Pretoria, South Africa.

10. Mooberry SL. Mechanism of action of 2-methoxyestradiol: new developments. Drug Resist Updat 2003; 6: 355361.

11. Sweeney C, Liu G, Yiannoutsos C, et al. 2 ME2 in multiple tumor types phase II multicenter, randomized, double-blind, safety trial assessing the pharmacokinetics, pharmacodynamics, and efficacy of oral 2methoxyestradiol capsules in hormone-refractory prostate cancer. Clin Cancer Res 2005; 11: 6625-6633.

12. Pribluda VS, Gubish ER, Jr, LaVallee TM, Treston A, Swartz GM, Green SJ. 2-Methoxyestradiol: an endogenous antiangio-genic and antiproliferative drug candidate. Cancer Metastasis Rev 2000; 19 : 173-179.

13. Seegers JC, Bohmer LH, Kruger MC, Lottering M-L, De Kock M. A comparative study of ochratoxin A-induced apoptosis in hamster kidney and HeLa cells. Toxicol Appl Pharmacol 1994; 129: 1-11.

14. Bradford MM. A rapid and sensitive method for the quantitation of microgram quantities of protein utilizing the principle of protein dye binding. Anal Biochem 1976; 72: 248-254.

15. Dingli D, Timm M, Russell SJ, Witzig TE, Rajkumar SV. Promising preclinical activity of 2-methoxyestradiol in multiple myeloma. Clin Cancer Res 2002; 8: 3948-3954.

16. Van Zijl MC. In vitro effects of 2-methoxyestradiol, an endogenous estrogen, on MCF-12A and MCF-7 cell cycle progression. M.Sc. Dissertation, 2006; Department of Physiology, University of Pretoria, Pretoria, South Africa.

17. Joubert A, Maritz C, Joubert F. Influence of prostaglandin $A_{2}$ and 2-methoxyestradiol on Bax and Bcl-2 expression levels in cervical carcinoma cells. Biomed Res 2005; 26: 87-90.

18. Joubert A, Maritz C, Joubert F. Bax/Bcl-2-expression levels of 2-methoxyestradiol-exposed esophageal cancer cells. Biomed Res 2005; 26: 131-134.

19. Wang $X$, Jin D-Y, Wong YC, et al. Correlation of defective mitotic checkpoint with aberrantly reduced expression of MAD2 protein in nasopharyngeal carcinoma cells. Carcinogenesis 2000; 21: 2293-2297.

20. Atalla H, Ma"kela“ TP, Adlercreutz H, Anderson LC. 2-Methoxyestradiol arrests cells in mitosis without depolymer-ising tubulin. Biochem Biophys Res Commun 1996; 228: 467-473.

21. Golebiewska J, Rozwadowski P, Spodnik JH, Knap N, Wakabayashi T, Wozniak M. Dual effect of 2methoxyestradiol on cell cycle events in human osteosarcoma 143B cells. Acta Biochim Pol 2002; 49: 59-65.

22. Lin H-L, Liu T-Y, Chau G-Y, Lui W-Y, Chi C-W. Comparison of 2-methoxyestradiol-induced, docetaxel-induced, and paclitaxel-induced apoptosis in hepatoma cells and its correlation with reactive oxygen species. Cancer 2000; 89: 983-994.

23. Andreassen PR, Margolis RL. Microtubule dependency of p34cdc2 inactivation and mitotic exit in mammalian cells. J Cell Biol 1994; 127: 789-802.

24. Burke DJ. Complexity in the spindle checkpoint. Curr Opin Genet Dev 2000; 10: $26-31$.

25. Canman JC, Sharma N, Straight A, Shannon KB, Fang G, Salmon ED. Anaphase onset does not require the microtubule-dependent depletion of kinetochore and centromere-binding proteins. J Cell Sci 2002; 115: 37873795.

26. Lundberg AS, Weinberg RA. Control of cell cycle and apoptosis. Eur J Cancer 1999; 35: 531-539. 